\title{
Languaging in and about Lunyole: African Storybook materials as a catalyst for re-imagining literacy teaching and learning in two Ugandan primary schools
}

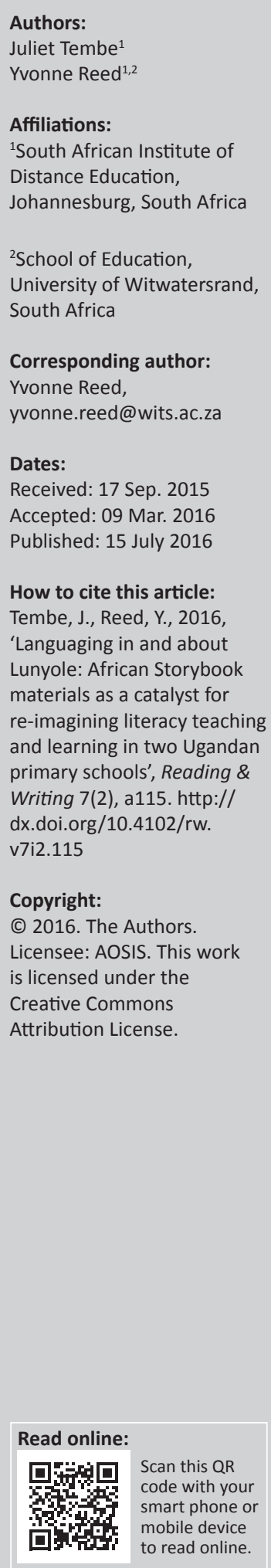

Throughout sub-Saharan Africa, many children are not learning to read competently in the first 3 years of primary school; thus, both 'reading to learn' and 'reading for pleasure' in these early years, and in higher grades, are constrained. Two of the many reasons for reading failure are the absence of suitable materials in languages with which learners are familiar and teachers' limited knowledge of pedagogic practices that support reading development. In this article, we describe the African Storybook (ASb) initiative as one imaginative response to the dearth of interesting and accessible stories in local languages and report findings from the first phase of a professional development project in which teacher-researchers in two Ugandan schools are using ASb materials to 'language' in Lunyole at the meetings of their action research group. We argue that their investment in extending their literacy in a language which they speak more fluently than they read or write, and the contestations over written forms of this language that have surfaced in some of the discussions, are likely to be productive for their professional development as teachers and for their participation in ongoing community debates about the orthography of a recently codified and standardised language. By languaging together in Lunyole, with ASb materials as the main object of their conversations and activities, the teacher-researchers have begun to develop capabilities that are likely to benefit the Lunyole/ English biliteracy of the learners whom they teach. They are imagining new possibilities for themselves and for the learners.

\section{Introduction}

In June 2015, USAID and the Uganda School Health and Reading Program (USHRP) reported findings from research into the reading achievements of Grades 1-3 learners in selected Ugandan schools. The recommendations section of this report reads as follows:

- Recommendations for improving reading achievement in Ugandan primary schools: Given the very low levels of reading achievement in both local languages and English and the situation in schools and classrooms, the following recommendations for moving forward in the area of support for reading reform in primary schools in Uganda include:

- Materials: Teachers need materials to teach reading (teachers guides and learner primers) but they also need to be trained in using these materials to benefit the learners. Classroom observation has found that even though learners have the materials, the teachers focus most on reciting from the board.

- Teacher training: Teachers need to be trained on the explicit teaching of reading, how to utilize the teaching materials and how to guide learners in the use of the learner materials. Teachers also need to be given guidance on regular lesson planning and assessing learner progress in foundational reading skills. Foundational pre-reading skills (such as print awareness) need to be an early focus.

- Teacher support: Even if trained, teachers need continued follow-up support for reading instruction in the classroom. Current evidence suggests that Co-ordinating Centre Tutors are not visiting schools often enough and head teachers (or other school based staff) are also not providing regular support and supervision of teachers in using the reading methodology. (USAID/Uganda School Health and Reading Program 2015:4)

While critical of some aspects of these recommendations (e.g. the entirely deficit construction of teachers), we acknowledge the reality of low levels of literacy achievement in many Ugandan primary schools, even when teachers and learners have access to sufficient resources (Busingye \& Najjuma 2015). As a response to the observation of Busingye and Najjuma (2015:124) that there is 
a need to 'tell stories behind the statistics' of wide surveys of the state of Ugandan primary school education, in this article we describe and reflect critically on one imaginative response to the concerns raised in the USAID/USHRP report: an action research project in which the Ugandan co-ordinator of the African Storybook (ASb) initiative is working with primary school teachers from two schools in the Butaleja District. Initially, the project co-ordinator had imagined that a series of after-school workshops would focus on how to make optimal use in the classroom of ASb materials that had been translated into Lunyole, the local language. While the teachers were interested in extending their pedagogic knowledge, their conversations from the first meeting onwards revealed curiosity about, and in some instances strongly held views, on the 'correctness' of the forms of Lunyole used in the ASb texts. The first Lunyole dictionary was published only recently, and this may be why debates about forms and meaning are much more 'alive' than for languages with orthographies that were settled long ago. We suggest that literate speakers of Lunyole are likely to imagine themselves as authorities in a way that literate speakers of standardised English or Luganda, to take two examples relevant to Uganda, are unlikely to do.

Before presenting a series of vignettes from the teachers' workshops which are the heart of the article, we outline the $\mathrm{ASb}$ initiative and its materials and the literature on which we have drawn in analysing the vignettes.

\section{The African Storybook initiative as an imaginative response to the Africa-wide shortage of texts in readers' primary languages}

While governments throughout Africa have made progress during the last decade towards achieving the goal of Education for All, it is still the case that after the first 3 years of primary education, many children have not learned to read well enough to enjoy reading and are not well equipped for reading to learn at the next level of schooling (Barrett 2015; Howie et al. 2008; Pretorius 2014; Tao 2015; UNESCO 2014; USAID \& Ugandan School Health and Reading Program 2015). The shortage of appropriate stories for early reading in languages with which children are familiar is one of the key obstacles to learning to read well (Parry, Andema \& Tumusiime 2005). The lack of texts in children's primary language(s) is of particular concern in bi- or multilingual education contexts in which learners are expected to be bi- or multiliterate and in which reading to learn in the higher grades is done in a language that is not their primary language. Pretorius (2014) quotes studies in bilingual reading research which have found that decoding skills can transfer across languages with an alphabetic written code and that the ability to identify setting, main characters, problems and resolutions in narratives and to identify main ideas, make inferences and use linguistic or text clues to construct meaning when reading expository texts, can also be transferred. Pretorius (2014:54) argues that in bilingual/ multilingual classroom contexts, it is 'important for learners to develop strong literacy skills as a basis for building academic literacy proficiency that can be shared across languages'.

As noted by Welch (2012), conventional publishing models which rely on economies of scale, are unable to provide texts in sufficient number or variety in the continent's multitude of languages, some of which are spoken by relatively small populations. The $\mathrm{ASb}$ initiative is an imaginative response to the need for many stories in many languages at little or no financial cost to readers. Under the leadership of the South African Institute for Distance Education (Saide), open access digital texts for early reading have been sourced from and translated into a total of 65 languages to date (January 2016) and uploaded onto a comprehensive website. Learners do not have to be online to read the texts: they and their teachers or caregivers can download them onto their own devices or print them, though we recognise that access to the resources with which to do this is still problematic in some contexts. Since the start of the ASb initiative in 2013, Saide has stimulated and managed story development, translation and adaptation in numerous ways: through partner-led workshops in a variety of contexts in sub-Saharan African countries as well as through integration of story development and translation into teacher education programmes. It is possible for story developers to create or translate or adapt a text offline and then upload it when the internet is available.

While some adaptations to texts focus on changes to a storyline or on provision of additional content for an information text, others involve the selection of simpler or more complex lexis and syntax to suit the level of the learners who will read the texts or adjustments to conform to the variety of a language spoken in a particular area (e.g. in South Africa, the Sepedi dialect called 'Pretoria' as distinct from the Sepedi spoken in the Limpopo Province). Although the project title suggests that all the texts are narratives (stories), this is not the case. Many are information texts and though the quality may be uneven (Janks \& Harley 2015), the best of these offer learners opportunities to extend what Cummins (2000) terms cognitive academic language proficiency through engaging with registers required for understanding and producing the discourses of various subjects in the school curriculum (e.g. science).

Researchers have established that the teaching of reading in the early grades has been given little attention in many teacher education programmes (Welch et al. 2015) and, that where these programmes do address reading pedagogy, teacher educators often assume that teachers can apply what they have learned about teaching reading in the dominant language of the education system (e.g. English) to teaching reading in the primary language of the learners. This is a problematic assumption, particularly in contexts where teachers are not confident readers and writers of the language which they and the children speak - a consequence of their formal education having been mainly in a language of wider communication, such as English or in an indigenous 
language chosen by the former colonial power, such as Luganda. This is the situation of the Lunyole-speaking teachers in the Buteleja District of Uganda whose participation in an ongoing teacher-researcher project facilitated by the ASb co-ordinator for Uganda is the focus of this article.

\section{The teacher-researcher project in the Buteleja District: imagining teachers as agents of change}

For Comber, the assumption that all students are capable of researching how language works, that all cultural groups have significant contributions to make to understandings of literate practices and that all texts should be subject to question is central to 'curriculum justice' for all (2016:5). This assumption underpins the small-scale research project described and discussed in this article, though in this instance the students are not the learners in classrooms about whom Comber writes, but their teachers. In conceptualising the project and in analysing data gathered during its initial stages, we have drawn on the theoretical constructs of 'teacher agency', 'capability', 'identity/ies', 'investment' and 'languaging', in each of which, in our view, imagination is implicated.

\section{Teacher agency}

In their exploration of the concept of teacher agency, Priestley, Biesta and Robinson (2012) focus on how agency is 'achieved' in concrete settings and under particular 'ecological' conditions. They argue that agency is not something that people can have but rather it is something that people do:

It denotes a 'quality' of the engagement of actors with temporalrelational-context-for-action, not a quality of the actors themselves. Viewing agency in such terms helps us to understand how humans are able to be reflexive and creative, acting counter to societal constraints, but also how individuals are enabled and constrained by their social and material environments. (Priestley et al. 2012:3; italics in the original)

For these authors, agency is concerned with intention to bring about a future that is different from the present and the past and situated within social structures and cultures that may, together with the presence or absence of material resources, enable or constrain its achievement (Priestley et al. 2012:3-4). While acknowledging the important influences of teachers' general life histories and of their specific professional histories (i.e. the 'past') on teacher agency, Priestley et al. argue that agency can only ever be 'acted out' in a present in which the actors 'make practical and normative judgements among alternative possible trajectories of action, in response to the emerging demands, dilemmas and ambiguities of presently evolving situations' (Emibayer \& Mische 1998, in Priestley et al. 2012:4). For theorists and education practitioners who offer 'capabilities' as an alternative to economic wealth as a measure of development (e.g. Baxen, Nsubuga \& Johanson Botha 2014; Sen 1999; Tikly \& Barrett 2011; Walker et al. 2009), 'agency and human flourishing are interlinked, since agency allows people to act on behalf of the goals for which they have reason to strive, while limited agency constrains one's ability to choose preferred functionings' (Baxen et al. 2014:96).

\section{Capabilities}

Walker et al. define capabilities as 'the real and actual freedoms (opportunities) that people have to do and be what they value being and doing' (2009:567) and capability as 'not just the opportunity for empowerment, or agency, but being able to exercise such agency in advancing the goals one values' (2009:568). In her work with teachers in Tanzania, Tao (2015) has argued for understanding what teachers value as a starting point for professional development. With reference to research in education, Baxen et al. consider a key question to be 'What factors influence the ability of education participants to convert educational resources into capabilities?' (2014:100).

\section{Identity and/or identities and investment}

Since 1995, Bonny Norton has been exploring the concepts of identity, investment and imagined communities both individually and also in collaboration with a wide range of scholars. In the revised second edition of Identity and language learning, subtitled Extending the conversation, Norton defines identity as 'how a person understands his or her relationship to the world, how that relationship is structured across time and space, and how the person understands possibilities for the future' (2013:45). In the Afterword to this second edition, Kramsch (2013) writes that Norton's notion of investment, originally conceptualised as a sociological complement to the psychological construct of motivation:

accentuates the role of human agency and identity in engaging with the task at hand, in accumulating economic and symbolic capital, in having stakes in the endeavour and in persevering in that endeavour. (p. 195)

In explaining one of the differences between motivation and investment, Darvin and Norton suggest that in addition to asking 'Are students motivated to learn a language?, researchers should ask the question 'Are students and teachers invested in the language and literacy practices of a given classroom and community?' (2015:37). In our view, this question echoes Tao's recommendation that designers and implementers of teacher professional development programmes begin by understanding what teachers value, as what they value is likely to be what they are prepared to invest in. Most contemporary conceptualisations of identity consider it to be 'fluid, multiple, and a site of struggle' (Darvin \& Norton 2015:37) and for this reason some prefer the term 'identities' (e.g. Gee 2001; Hall 1996). 
We suggest that the four constructs briefly outlined thus far are important for the design and evaluation of any professional development programme and that imagination is central to each of them: new ways of teaching and new teacher and learner identities need to be imagined as a starting point for explorations of new ways of being and doing and as the explorations proceed, each of these is likely to be re-imagined.

The final construct below is of a different order. It is an umbrella term for the particular activity of making meaning with and through language, an activity that involves using language imaginatively and creatively.

\section{Languaging}

In a chapter titled 'Languaging, agency and collaboration in advanced second language proficiency', Swain (2006) describes languaging as:

the process of making meaning and shaping knowledge and experience through language. Languaging about language is one of the ways we learn language. This means that the languaging (the dialogue or private speech) that learners engage in takes on new significance. In it, we can observe learners operating on linguistic data and coming to an understanding of previously less well understood material. In languaging we see learning taking place. (p. 98)

In similar vein, for Lankiewicz, languaging is 'a dynamic social phenomenon with the language system idiosyncratically constructed by its users' (2014:17). Both authors acknowledge Vygotsky's insight that language is one of the most important mediating tools of the mind, with Swain emphasising the value of what she and her colleague Lapkin have termed 'talking-it through', 'to another, with another or with the self' (2006:97). Through an analysis of conversations of pairs of English second-language learners, in which they discuss aspects of their linguistic, social and cultural knowledge of English, Swain (2006:105) demonstrates how these language learners extend their competence and confidence in using the target language as a result of languaging about language. In their conversations, they identify things about the target language that they do not know and set about trying to solve the problem, using language to mediate their thinking.

The teacher-researchers participating in the action research project described and discussed in this article are not engaged in learning a new language but in languaging about the written forms of a language in which they are expert speakers but novice readers and writers. Before turning to vignettes from the professional development meetings during which they engaged in languaging, we briefly outline our understanding of action research.

\section{Action research}

Although action research has been described as 'a very broad church' (Kemmis \& McTaggart 1987), two words often used to distinguish it from other approaches to research are 'involvement' and 'improvement': involvement of the researcher(s) in the social situation they are researching with the aim of bringing about improvements in policy, practices and environments. For example, Kemmis and McTaggart (1988) define action research as:

... a form of collective self-enquiry undertaken by participants in social situations in order to improve the rationality and justice of their own social or educational practices, as well as the situations in which these practices are carried out. (p. 55)

While an 'enquiry spiral' (identifying a concern or issue, undertaking reconnaissance, planning, taking action steps, evaluating, amending the plan, taking further action, etc.) is characteristic of action research, researchers may use a wide range of methods for collecting and analysing data. McTaggart (1996) cautions that the spiral should not be considered as a template for practising action research, and McNiff (1988) demonstrates how 'auxiliary spirals' may become a productive focus of enquiry in addition to or in place of what had been identified initially as a central concern. While collection and analysis of data should be done with the same rigour as for any other type of empirical research, McTaggart (1996), McNiff (1988) and others (e.g. Stringer 2007) stress the importance of responsiveness to the interests of participants in the enquiry, which may result in changes of focus during the life of a research project. As will be described below, what the authors had identified as the central concern to which they and a group of teachers would respond, was not the teachers' first priority and as a result, the primary focus of the investigation changed at the outset but in ways that, in our view, have been productive for the teachers' professional development and for literacy teaching and learning in their classrooms.

\section{Telling a research story}

In Case Study Research in Educational Settings, Bassey (1999) describes three types of educational case study: theoryseeking and theory testing; story-telling and picture-drawing; evaluative. He defines story-telling and picture-drawing case studies as 'narrative stories and descriptive accounts of educational events, projects, programmes, institutions or systems which deserve to be told to interested audiences, after careful analysis' (Bassey 1999:58). Bassey draws on the work of Stenhouse to advocate the use of 'short descriptive pieces' or 'vignettes' in the reporting and discussion of research findings in order to 'crystallise important aspects of a case' (Stenhouse 1988:52, in Bassey 1999:88). In our attempt to tell a story of the teacher-researchers at work, we present a series of vignettes which we then discuss in the final part of the article.

\section{The research context}

In Uganda, teachers are expected to teach Grades 1-4 learners to become literate in the dominant local language and to use this language as medium of instruction (Ministry of Education and Sport, Uganda; National Curriculum Development Centre, Uganda 2007, in Heugh \& Mulimba 2013:17). It is important to 
note that in the Buteleja District in south-eastern Uganda, while Lunyole is the dominant local language, in the colonial era formal education was first introduced in Luganda and this language is still used in churches, the lower courts and health centres (Tembe \& Norton 2008). Tembe and Norton note that the orthography for Lunyole was developed only in 2003 through the Lunyole Language Association in partnership with the Summer Institute of Linguistics. Prior to the introduction of the ASb texts, few literacy materials in Lunyole were available to teachers.

\section{The research participants and the research process}

When the ASb co-ordinator invited teachers from two neighbouring primary schools to become teacher-researchers who would investigate with her how to use ASb texts in Lunyole productively in the classroom, six teachers and the principal of one of the schools responded enthusiastically. However, they requested that the initial focus of the research meetings should be on extending their own knowledge of reading and writing in Lunyole. As noted by Tembe and Norton (2008:37), when literacy is theorised as a social practice, it is necessary to understand it 'both locally and historically, as well as with reference to the social relationships in which speakers, readers and writers find themselves'. We suggest that a possible reason for the teachers' request was that for the first time they had access to a range of texts in Lunyole and thus could see value in being literate in it - both for themselves and for the learners in their classrooms. While the co-ordinator agreed that the workshops would focus on the teachers' Lunyole language literacy, almost from the start conversations and activities included imagining how to 'transfer' what the teachers were learning through their languaging activities to their classroom practices. Nevertheless, the main research question changed. The original question, 'Could professional development activities based on ASb stories in Lunyole be productive for literacy teaching and learning?' had been formulated in discussions between the ASb co-ordinator and the co-author of this article in the role of 'critical friend'. It was modified to become 'Could group reading and discussion of $\mathrm{ASb}$ stories in Lunyole lead to increased teacher competence and confidence in reading and writing in Lunyole and to greater use of Lunyole in the classroom?'

The group agreed to meet for two hours after school, either once or twice a week (depending on school commitments) for the duration of a school term, at the end of which they would reflect critically on the research question and make decisions about the future of the research group. Each teacher recorded notes at each meeting and at some of the meetings prepared materials for use in their classrooms. The ASb co-ordinator recorded field notes during the meetings, wrote reflections in her journal after each meeting and emailed these, together with photographs of the group at work, to her critical friend for discussion in email conversations. At the final meeting of the first phase of their work, the teacher-researchers wrote individual reflections and used these in a critical group reflection and to make plans for the second term. In the next part of the article, we present eight vignettes from the data collected from teachers' materials, the ASb co-ordinator's field notes and reflective journal, the email conversations and the end-of-term reflections of the whole research group and then reflect on what we think these vignettes 'tell' us.

\section{Languaging about an African Storybook story}

At the second meeting of the group, the teacher-researchers read an ASb first-sentence story Ono indiise (This is me). In doing so, they took turns to read sentences, at times suggesting corrections to each other's pronunciation and afterwards discussed the spelling of particular words and the punctuation of the sentences. For example, while the word hifanani is used in the story, the group agreed that the word in common usage is hifananyi and that they would tell learners this when reading the story with them. As a group, they decided that it would be helpful to learners to use the phrase hifananyi hiranyi to generate further words beginning with $h i$ and that they would begin with Higalamu (It is wide), Himaali (It is black), Hihosa (It is white) and Hirando (It is red) (sources: teachers' notes; ASb co-ordinator's field notes; sentence chart prepared by teachers).

\section{Languaging about the Lunyole alphabet}

In discussing the Lunyole alphabet and the spelling of some of the words in the ASb stories, the group focused on comparisons and contrasts with the alphabet/spelling in English and in Luganda. The co-ordinator recorded the following observations made by the teachers:

- Neither $x$ nor $q$ is used in Lunyole.

- Lunyole uses a long-tailed $\mathrm{y}$.

- Words with a $v$ or $z$ as first letter are borrowed (e.g. vumbula from Luganda).

- $\quad b$ is the only consonant that can be doubled (plosive $b b$ ).

- The consonant before any word ending in a vowel must be $r$ (e.g. muliro).

- In Lunyole, repetition of a vowel affects meaning: Baasaala (I was born), Basaala (They produce) (Source: ASb coordinator's field notes).

\section{Languaging about thematic vocabulary}

The group read the English version of the ASb story The Letter and discussed how they could translate it into Lunyole and then prepare a bilingual vocabulary chart for learners. During the session, they compiled a 15-item poster titled At the hospital and in the process became aware of the challenge for translators, and for early-grade learners, of words with multiple meanings. The following are some examples from the poster:

$\begin{array}{ll}\begin{array}{l}\text { Lunyole } \\ \text { egangiro }\end{array} & \begin{array}{l}\text { English } \\ \text { hospital } \\ \text { omugangi }\end{array} \\ & \begin{array}{l}\text { doctor / nurse (but noted in discussion that } \\ \text { this word also means 'a load' }\end{array} \\ \text { omulwaye } & \begin{array}{l}\text { patient } \\ \text { amalesi }\end{array} \\ \text { drugs }\end{array}$


episo

syringe (but noted in discussion that this word also means 'a needle for sewing clothes')

(Sources: poster; ASb co-ordinator's field notes)

\section{Languaging with a Lunyole language expert}

The chairperson of the Lunyole Language Association joined the research group for the reading and discussion of the $\mathrm{ASb}$ story Goat, dog and cow, which had been translated into Lunyole. During the discussion, several teachers recommended changes to words they considered inappropriate in the context of the story and in two instances politely disagreed with the LLA chairperson's choice of vocabulary for the story. He agreed with their suggested changes and subsequently the translation was revised, a new translation uploaded and the senior story editor informed of the change (source: ASb coordinator's field notes).

\section{Languaging during a collaborative writing exercise}

Each teacher drafted a version in Lunyole of the same story and then shared it with the group. Ideas, words and phrases from these individual stories were then selected for one group story, the first version of which was written on flip chart paper by the co-ordinator in response to dictation from the teachers. As a group they then decided on improvements to the storyline, grammar, vocabulary and spelling. The co-ordinator noticed that teachers were more interested in writing information texts than imaginative stories and also more interested in 'correct' than playful use of language (sources: teacher's draft stories; combined and revised story on flip chart paper; ASb coordinator's field notes and journal reflections).

\section{Sharing teaching strategies}

Towards the end of the first term, one of the meetings focused on pedagogy. In discussing the drawings in the ASb stories, the teachers agreed that these assisted reading comprehension. One teacher told the group that she planned to bring objects, photographs or drawings to class to help learners with word meanings in both Lunyole and English. Her idea was taken up by the whole group, with each teacher agreeing to include objects or images or both in their literacy lessons, to make notes on learners' responses and to bring these notes to a group meeting for discussion. Two teachers showed the group a shortened version of an ASb story and explained how they used this adapted story in numeracy lessons to teach subtraction. In the final part of the meeting, the group discussed learners' difficulties with prepositions in Lunyole: in a written text they are separate words but many learners appear to hear them as part of the adjacent word. Everyone agreed to bring suggestions for tackling this problem to the next meeting (sources: teachers' notes; ASb co-ordinator's field notes).

\section{Becoming ambassadors for Lunyole-in-education}

The co-ordinator recorded two examples of what we consider to be shifts in teacher identity after participating in the research project for one term. Firstly, at a regional Ministry of Education workshop, in response to a question about whether to teach in
Lunyole or English, the teachers participating in the action research project argued in favour of Lunyole and were the only ones to do so. Secondly, the teacher-researchers have submitted a request to the USHRP, run by RTI International, that teachers' and learners' books be translated from Luganda, one of the 'cohort languages' in the programme, into Lunyole, a language not currently part of the programme. One of the advantages of having these materials translated into Lunyole is that the RTI materials are now available for downloading under a Creative Commons agreement.

\section{Reflecting on languaging experiences during the first research cycle and making plans for the second cycle}

The comments below are representative of the positive and negative reflections on the experience of participating in the group's activities that were recorded by individual teachers, read to the group and recorded on flip chart paper by the coordinator.

\section{The positive}

'I can read and write mother tongue words'.

'I can read the mother tongue alphabet'.

'I've learnt a lot about the Lunyole alphabet and spelling and the use of Lunyole prepositions'.

'I'm learning how to write the grammar'.

'Workshops have helped me to learn how to teach in the literacy hour'.

'I can write a story in mother tongue, considering the age level of classes'.

'Children are now participating actively in my lessons'.

'I used to contest teaching in the mother tongue but now I'm interested'.

'In our group we gain knowledge by consensus'.

'At the meetings people trusted me and shared with me wholly and willingly'.

\section{The negative}

'The time is not enough for professional development'.

'The lack of support from the Department of Education is disappointing'.

'I need more books in Lunyole'.

'I'm disappointed that I still can't create rhymes and tongue twisters'.

'Some children are slow learners in mother tongue'.

'It's difficult to help all the children because my class is so big'.

'I have little knowledge about ICT (use of lap top)'.

\section{Plans for the second cycle}

'Write stories together on the term's themes'.

'Have more workshops on teaching reading in early grades'.

'Keep going with Lunyole language work'.

\section{Discussion}

Saide's vision is that 'every African child have enough stories in a language familiar to them to practise their reading skills and learn to love reading' (Saide pamphlet on the ASb initiative, no date). Turning the imagined into reality involves 
not only designing, producing and supplying texts but also facilitating teachers' exploration of their attitudes, values and pedagogic practices in relation to language and literacy inside and outside the classroom. In our view, ASb stories in Lunyole as a vehicle for languaging in and about Lunyole have contributed to teacher-researchers 'ownership' of the language of their homes and community, one result of which has been challenges to aspects of its recent codification and standardisation (evident in their contestation of word forms in some of the ASb texts expressed in vignettes 1,2 and 4). However, as pointed out by one of the reviewers of this article, the ideological question of whose 'voice' is to be authoritative in regard to the written form(s) of a language is a complex one, given that there may be a variety of dialects, even in such a local language as Lunyole. With reference to stories on the ASb website in the isiNdebele and siSwati languages, Jiyana and Ndlovu (2015) have proposed that stories in different varieties of the same language be given an identifying tag: siSwati (Swaziland); siSwati (South Africa); northern Ndebele (South Africa); southern Ndebele (South Africa); Ndebele (Zimbabwe). However, a question raised by teachers' concern with 'correctness' is whether this may lead to their privileging of texts which in their view exemplify such correct use of language over texts which are likely to engage learners' interest because of the quality of the story and/or images but which may include what these teachers consider to be linguistic 'errors'.

In their mid-term review of the ASb initiative, Janks and Harley (2015:ii) note what they term 'the utilitarian orientation to literacy' of most of the teachers whom they observed using the materials at the pilot implementation sites. For these reviewers, teachers' preference for non-fiction, information curriculum-related stories or stories with a moral 'raises questions about the value of narrative fiction and the pleasure principle in relation to literacy in African communities' (Janks and Harley 2015:ii). While we agree that such questions are important, we suggest that 'the pleasure principle' can be imagined in different ways. The teacherresearchers took pleasure in the achievement of knowledge of the written form(s) of their mother tongue (vignettes 1, 2, $3,5,8)$, in their evolving knowledge of new pedagogic strategies (vignettes 3, 6 and 8) and in their evolving capability to produce teaching materials (vignette 8 , Term 2 plan: 'Write stories together on the term's themes'). In Priestley et al.'s (2012) terms, through languaging together about the Lunyole language the teacher-researchers have acted agentively to extend their knowledge of the written forms of their language and in the process there has been identity shift along a continuum from novice to expert, with individual teachers imagining themselves in different positions along this continuum ('I've learnt a lot'; 'I'm learning how ...'). With knowledge comes both agency and capability to participate in conversations with a language expert and even to challenge this expert (vignette 4), to advocate the use of the learners' mother tongue in the classroom (vignette 7) and to request teaching and learning materials in Lunyole from a programme that provides these in the dominant local languages (vignette 7). Each of these actions suggests an identity shift in terms of attitude to one's home language and in terms of confident professional identity. However, it should be noted that there is also evidence in the vignettes of constraints on capability ('The lack of support from the Department of Education is disappointing'; 'I have little knowledge of $\mathrm{ICT}^{\prime}$; It's difficult to help all the children because my class is so big') and of a preoccupation with 'correctness' which may have a negative influence on text choice.

In any pilot project, one of the questions to be addressed is that of long-term sustainability. In the formation of the teacherresearcher group in the Buteleja District and in the facilitation of its meetings, the ASb co-ordinator has played a key role to date. However, there have already been occasions on which the group has met without her and continued its languaging activities and in the final vignette there are two causes for optimism that the teachers will continue to invest in their professional development. Firstly, there is evidence of an incipient professional learning community ('In our group we gain knowledge by consensus'; At the meetings people trusted me and shared with me wholly and willingly'). Janks and Harley consider 'a strong sense of community' to be a likely indicator of sustained and productive use of the ASb materials: 'The more the teachers support one another the greater the gains. The more there is a sense of community within the school and out to the local community, the more excited the teachers become' (2015:ii). Secondly, the plans for the next term's meetings (vignette 8), though quite general in their formulation, suggest continued investment in their own learning and in that of the children in their classes whose identities at least some of the teachers now construct as active rather than passive learners and as learners who will benefit from learning to read and write in their mother tongue (vignettes 6 and 8). What requires further exploration is whether languaging around stories could be the starting point for systematic joint lesson planning and materials development to support the learning of both Lunyole and English.

In this article, our focus has been on imagination exercised by materials developers and providers (the ASb initiative) and by teacher-researchers (early-grade teachers in two Ugandan primary schools) rather than by child learners. However, we suggest that stimulating materials - in learners' home languages, in dominant regional languages and in global languages - have the potential to be a catalyst for classroom teaching that opens up imaginative possibilities for learners to enjoy becoming readers and writers of texts in multiple languages and language varieties. Equally important is an open licence digital publishing model such as that of the ASb initiative because this allows readers and writers to be authorities on languages and language varieties, to imagine new versions of texts and to submit these for inclusion on the site alongside other versions. In response to the challenging question of whose language ideology should 'count' in particular sociocultural contexts, we suggest that this 
publishing model enables a partial answer: not ours or theirs but ours and theirs (Collins 1998).

\section{Acknowledgements}

We are grateful to Tessa Welch for her insightful comments on a draft version of this article and to the reviewers to whose incisive critique we have attempted to respond.

\section{Competing interests}

The authors declare that they have no financial or personal relationships which may have inappropriately influenced them in writing this article.

\section{Authors' contributions}

Juliet Tembe facilitated the teachers' meetings and the article was equally written by both authors.

\section{References}

Barrett, A., 2015, 'Measuring literacy post-2015: Some social justice issues', in H. Mcllwraith (ed.), Language Rich Africa Policy Dialogue: The Cape Town Language and Development Conference, Looking Beyond 2015, British Council, London.

Bassey, M., 1999, Case study research in educational settings, Open University Press, Buckingham.

Baxen, J., Nsubuga, Y. \& Johanson Botha, L., 2014, 'A capabilities perspective on education quality: Implications for foundation phase teacher education programme design', Perspectives in Education 32(4), 93-105. http://dx.doi.org/10.1080/18146 design', Perspectives

Busingye, J.D. \& Najjuma, R., 2015, 'Do learning and teaching materials influence learning outcomes amidst high enrolments? Lessons from Uganda's Universal Primary Education', Africa Education Review 12(1), 109-126.

Collins, J., 1998, 'Our ideologies and theirs', Pragmatics 2(3), 405-415.

Comber, B., 2016, Literacy, place and pedagogies of possibility, Routledge, New York. Cummins, J., 2000, Language, power and pedagogy, Multilingual Matters, Clevedon.

Darvin, R. \& Norton, B., 2015, 'Identity and a model of investment in applied linguistics', Annual Review of Applied Linguistics 35(2015), 36-56. http://dx.doi. org/10.1017/S0267190514000191

Gee, J.P., 2001, 'Identity as an analytic lens for research in education', Review of Research in Education 25, 99-125.

Hall, S., 1996, 'Introduction: Who needs “Identity"?', in S. Hall \& P. du Gay (eds.) Questions of cultural identity, Sage, London.

Heugh, K. \& Mulimba, B., 2013, An evaluation of the Literacy and Basic Education (LABE) Mother-Tongue Education (MTE) Project in Uganda. Final report. (No further details given)

Howie, S., Venter, E., Van Staden, S., Zimmerman, L., Long, C., Du Toit, C. et al., 2008, PIRLS 2006 summary report. South African Children's Reading Achievement, Centre for Evaluation and Assessment, University of Pretoria, Pretoria.
Janks, H. \& Harley, K., 2015, Mid-term review of African storybook project, Saide, Johannesburg.

Jiyana, W. \& Ndlovu, C., 2015, 'Addressing a literacy gap: Student teachers as translators and evaluators of stories in siSwati and isiNdebele for Foundation Phase classrooms', paper presented at the South African Education Research Association (SAERA) Conference, University of the Free State, October 2015.

Kemmis, S. \& McTaggart, R., 1987, The action research reader, 2nd edn., Deakin University Press, Geelong.

Kemmis, S. \& McTaggart, R., 1988, The action research planner, 3rd edn., Deakin University Press, Geelong.

Kramsch, C.J., 2013, 'Afterword', in B. Norton (ed.), Identity and language learning: Extending the conversation, 2 nd edn., Multilingual Matters, Bristol.

Lankiewicz, H., 2014, 'From the concept of languaging to L2 pedagogy', in H. Lankiewicz \& E. Wasikiewicz-Firlej (eds.), Languaging experiences: Learning and teaching revisited, Cambridge Scholars Publishing, Newcastle.

McNiff, J., 1988, Action research: principles and practice, Macmillan Education, Basingstoke.

McTaggart, R., 1996, 'Issues for participatory action researchers', in O. Zuber-Skerritt (ed.), New directions in action research, Falmer Press, London.

Norton, B., 2013, Identity and language learning: Extending the conversation, 2nd edn., Multilingual Matters, Bristol.

Parry, K., Andema, S. \& Tumusiime, L., 2005, Literacy for All in Africa: Teaching reading in African schools, Fountain Publishers, Kampala.

Pretorius, E., 2014, 'Supporting transition or playing catch-up in grade 4? Implication for standards in education and training', Perspectives in Education 32(1), 51-76.

Priestley, M., Biesta, G. \& Robinson, S., 2012, Teachers as agents change: An exploration of the concept of teacher agency, Working Paper No. 1, Teacher Agency and Curriculum Change, University of Stirling, Stirling.

Sen, A.K., 1999, Development as freedom, Oxford University Press, Oxford.

Stringer, E.T, 2007, Action Research: A handbook for practitioners, Sage, Newbury Park.

Swain, M., 2006, 'Languaging, agency and collaboration in advanced second language proficiency', in H. Byrnes (ed.), Advanced language learning: The contribution of Halliday and Vygotsky, Continuum, London.

Tao, S., 2015, Using the capability approach to improve the efficacy of teacher training, Cambridge Education, Cambridge.

Tembe, J. \& Norton, B., 2008, 'Promoting local languages in Uganda Primary Schools: The Community as Stakeholder', The Canadian Modern Language Review 65(1), 33-60. http://dx.doi.org/10.3138/cmlr.65.1.33

Tikly, L. \& Barrett, A.M., 2011, 'Social justice, capabilities and the quality of education in low income countries', International Journal of Education Development 31(1), 3-14. http://dx.doi.org/10.1016/j.ijedudev.2010.06.001

USAID/Uganda School Health and Reading Program, 2015, Cluster 3 baseline report, June 2015.

Walker, M., McLean, M., Dison, A. \& Peppin-Vaughan, R., 2009, 'South African universities and human development: Towards a theorisation and operationalisation of professional capabilities for poverty reduction', Internationa Journal of Educational Development 29, 565-572. http://dx.doi.org/10.1016/j. ijedudev.2009.03.002

Welch, T., 2012, 'Why mother tongue literacy isn't working: Policy, pedagogy, parents and publishing', Address to the Annual General Meeting of the Witwatersrand Council of Education, Wits School of Education, Johannesburg, October 09, 2012

Welch, T., Tembe, J., Wepukhulu, D., Baker, J. \& Norton, B., 2015, 'The African Storybook project: An interim report', in H. Mcllwraith (ed.), Language Rich Africa Policy Dialogue: The Cape Town Language and Development Conference, Looking Beyond 2015, British Council, London. 